\title{
Common Reference-Based Tandem Mass Tag Multiplexing for the Relative Quantification of Peptides: Design and Application to Degradome Analysis of Diphtheria Toxoid
}

Thomas J. M. Michiels, * Madelief A. van Veen, Hugo D. Meiring, Wim Jiskoot, Gideon F. A. Kersten, and Bernard Metz

Cite This: J. Am. Soc. Mass Spectrom. 2021, 32, 1490-1497

Read Online

ABSTRACT: Currently, animal tests are being used to confirm the potency and lack of toxicity of toxoid vaccines. In a consistency approach, animal tests could be replaced if production consistency (compared to known good products) can be proven in a panel of in vitro assays. By mimicking the in vivo antigen processing in a simplified in vitro approach, it may be possible to distinguish aberrant products from good products. To demonstrate this, heatexposed diphtheria toxoid was subjected to partial digestion by cathepsin S (an endoprotease involved in antigen processing), and the peptide formation/degradation kinetics were mapped for various heated toxoids. To overcome the limitations associated with the very large number of samples, we used common reference-

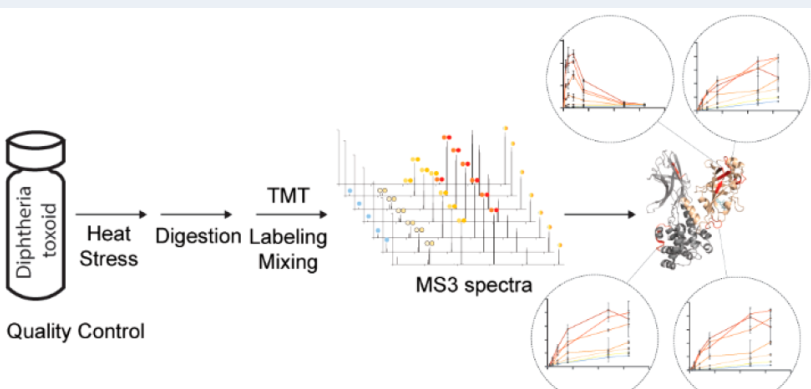
based tandem mass tag (TMT) labeling. Instead of using one label

Peptide-level degradation kinetics per condition with direct comparison between the set of labels, we compared multiple labeled samples to a common reference (a pooled sample containing an aliquot of each condition). In this method, the number of samples is not limited by the number of unique TMT labels. This TMT multiplexing strategy allows for a 15-fold reduction of analysis time while retaining the reliability advantage of TMT labeling over label-free quantification. The formation of the most important peptides could be followed over time and compared among several conditions. The changes in enzymatic degradation kinetics of diphtheria toxoid revealed several suitable candidate peptides for use in a quality control assay that can distinguish structurally aberrant diphtheria toxoid from compliant toxoids.

KEYWORDS: diphtheria toxoid, vaccine quality control, proteomics, tandem mass tag multiplexing, enzyme kinetics, degradomics

\section{INTRODUCTION}

Degradomics analysis of antigens and allergens has been successfully used for predicting $\mathrm{T}$-cell epitopes ${ }^{1}$ and for studying allergens and antigens. ${ }^{2-9}$ Usually, an antigen of interest is subjected to limited proteolysis in an in vitro setting which mimics antigen processing of the immune system. In vitro proteolysis can be done in isolated antigen-presenting cells (APCs), ${ }^{10}$ endolysosomal extracts of APCs, ${ }^{11,12}$ a mixture of APC-derived enzymes and proteins, ${ }^{1}$ or recombinant enzymes. ${ }^{9}$ In most applications the formed peptides are identified after a set time point by using liquid chromatography-tandem mass spectrometry (LC-MS/MS) for protein identification.

We have previously developed a degradomics-based analysis that can be used as a quality control (QC) assay for tetanus toxoids as an alternative for the animal tests that are currently being used to confirm potency and lack of toxicity of these vaccines. ${ }^{13}$ The rationale for this type of assay is that if the assay (or a panel of assays) can confirm batch-to-batch consistency, the potency and safety profile of the batches are also consistent.
Toxoids are prepared by formaldehyde-inactivation of toxins, which results in very heterogeneous mixtures due to a myriad of chemical modifications of the antigen. ${ }^{14}$ These modifications are most common in arginine, tyrosine, and lysine residues but are certainly not limited to these amino acid residues. This heterogeneity is further exacerbated by adsorption to colloidal aluminum salts. These salts enhance immunogenicity but lead to challenging characterization of the final vaccine. In the previously described assay, tetanus toxoids were exposed to elevated temperatures to simulate aberrant batches. Subsequently, the samples were subjected to digestion with recombinant cathepsin S. By using label-free quantification of

Received: February 23, 2021

Revised: April 23, 2021

Accepted: April 23, 2021

Published: May 13, 2021 


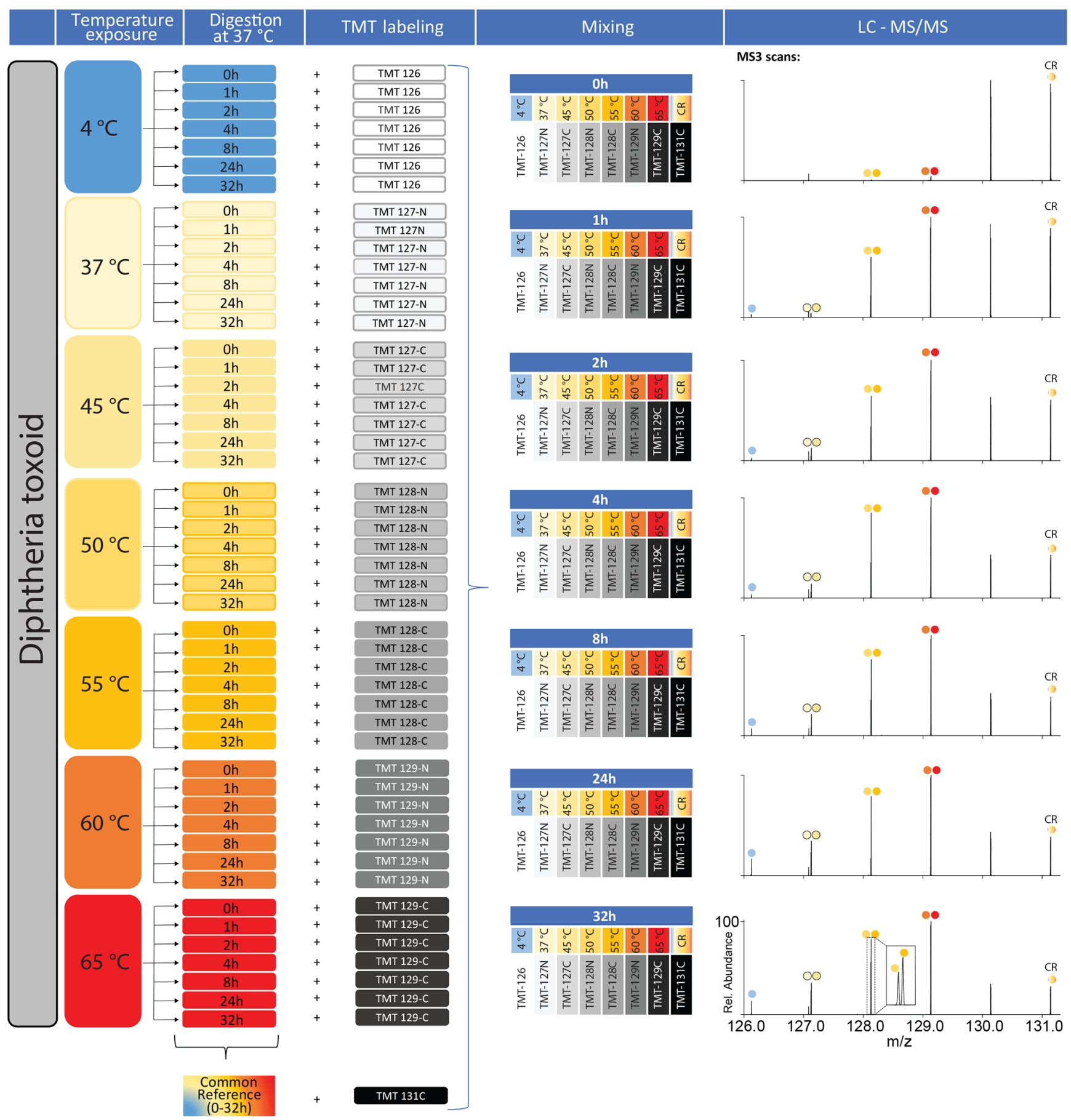

Figure 1. Schematic overview of the common reference-based tandem mass tag labeling strategy. Diphtheria toxoid was exposed to various temperatures and subsequently digested by cathepsin $S$ at $37^{\circ} \mathrm{C}$. The enzymatic reaction was stopped at various digestion time points. Aliquots of each sample were pooled to form a common reference sample. Subsequently, each sample was labeled with a unique TMT label for every temperature (the same TMT channels were used for the same exposure temperature) and a unique label for the pooled common reference sample (TMT ${ }^{11}$-131C). Since each digestion sample (time point and temperature) was prepared in triplicate, there was an opportunity for extra pooled control samples, made by labeling a pooled sample containing just one triplicate. These additional controls were labeled with $\mathrm{TMT}^{11}-130 \mathrm{~N}, \mathrm{TMT}^{11}-130 \mathrm{C}$, and TMT ${ }^{11}-131 \mathrm{~N}$, one for each triplicate. For simplicity, these are not depicted in the schematic overview (except for the MS3 spectrum). After labeling, the various heatexposed samples were mixed with the other heat-exposed samples of the same time point and with the common reference. The mixed samples were then measured by nanoscale LC-MS, identified by MS1 and MS2, and quantified by the reporter ions generated in MS3. The reporter ions can be compared to the common reference reporter ion $\left(\mathrm{TMT}^{11}-131 \mathrm{C}\right)$ for every separate analysis, allowing for comparison between different runs (i.e., different time points and replicates). The peptide used for the MS3 spectra in this example is YPGLT.

the peptides formed at various time points, the kinetics of the individual peptides were mapped. In subsequent analyses, selected peptides that showed temperature-induced differences in their formation/degradation kinetics were quantified by addition of synthetic isotopically labeled standards, which could reliably distinguish denatured products from unaltered products. We intend to apply similar degradomics analysis to other antigens where animal tests are still being used for QC, starting 
with diphtheria toxoid (DTd). The diphtheria toxin is a $58 \mathrm{kDa}$ protein consisting of an $\mathrm{A}$ and $\mathrm{B}$ fragment, which are connected by a disulfide bridge. In this study, the purified bulk was analyzed. Digestion of DTd with chymotrypsin (comparable to cathepsin S: a clear preference for cleavage sites but not completely specific) results in the identification of approximately 150-300 peptides with modern equipment, ${ }^{14}$ but the number of very abundant peptides is more limited, ${ }^{15}$ which is comparable to digestions of other purified proteins of a similar size. The first step in the development of a degradomics assay involves mapping the kinetics of as many as possible of the peptides that are formed by cathepsin $S$ digestion. Once the degradation process has been mapped, the assay can be simplified for use in QC by quantification of specific stabilityindicating peptides. Despite its simple sample preparation, the previously used unbiased label-free quantification for mapping the enzymatic degradation of tetanus toxoid has several disadvantages. In particular, the analysis time of approximately a week to analyze all samples is long, with the available instrument time usually being a limiting factor. Further disadvantages inherent to label-free quantification are interrun variability (worsened by the long overall analysis time) and susceptibility to ion suppression or enhancement. ${ }^{16}$

To overcome these issues, we looked into isobaric labelingbased relative quantification (reviewed by Rauniyar et al. and Arul et al. ${ }^{17,18}$ ) and specifically the use of tandem mass tag (TMT) labeling. ${ }^{19}$ The main drawback of standard isobaric labeling is the limited number of available labels/channels. Efforts are being made to increase the number of channels by designing new labels, such as TMTpro 16-plex, ${ }^{20}$ but this approach will eventually be limited by the size of the molecules, the limits of isotope incorporation and the mass spectrometric specifications (in particular its resolving power). Instead of using more channels to cover both of our variables (temperature exposure and enzymatic digestion time of the protein), we used a strategy in which different channels are used for one variable (temperature exposure) and in which one or more dedicated channels are used for a pooled sample (referred to as the common reference (CR), containing an aliquot of each of the samples). This results in a control that can be used for relative quantification between all samples because the common reference content is identical in each sample (Figure 1). Similar pooling strategies are common in quantitative DNA or RNA studies $^{21}$ and are used in the field of proteomics in conjunction with dimethyl labeling ${ }^{22}$ and TMT labeling. ${ }^{23-25}$ In this study, we report the use of the TMT-CR multiplexing strategy for mapping the enzymatic degradation kinetics of DTd solutions that were exposed to elevated temperatures to simulate faulty batches.

\section{MATERIALS AND METHODS}

Preparation of Aberrant Diphtheria Toxoids. Diphtheria toxoid was obtained from a manufacturer within the IMIfunded VAC2VAC consortium. ${ }^{26}$ The protein concentration (determined by BCA (Thermo Fisher)) was adjusted to $100 \mu \mathrm{g} /$ $\mathrm{mL}$. The toxoid was then thoroughly dialyzed (Slide-A-Lyzer Dialysis cassettes 10000 MWCO, Thermo Scientific) against a phosphate buffer $(10 \mathrm{mM}, \mathrm{pH} 7.2$, prepared from a $1 \mathrm{M}$ solution from Sigma-Aldrich). The protein concentration was confirmed to still be approximately $100 \mu \mathrm{g} / \mathrm{mL}$ by BCA. Subsequently, aliquots of the toxoid were incubated at different temperatures. Three samples were prepared per incubation temperature. The samples were incubated at $4,37,45,50,55,60$, and $65^{\circ} \mathrm{C}$ for 2 days.

Digestion Conditions. A $5 \mu \mathrm{g}$ sample of heated DTd was digested with cathepsin $\mathrm{S}(0.1 \mu \mathrm{g})$ in $100 \mu \mathrm{L}$ of sodium citrate buffer (100 mM, pH 5.0) containing $2 \mathrm{mM}$ dithiothreitol and 2 $\mathrm{mM}$ ethylenediaminetetraacetic acid. For each temperature (in triplicate) and time point, a separate reaction was carried out. The digestion took place at $37^{\circ} \mathrm{C}$ and was stopped by addition of $50 \mu \mathrm{L} 0.1 \mathrm{mM}$ E-64 solution (a cysteine protease inhibitor, Sigma-Aldrich).

Labeling. Prior to labeling, solid-phase extraction (SPE) was performed by using $50 \mathrm{mg}$ Sep-Pak C18 cartridges (Waters) in conjunction with a Gilson GX-271 ASPEC robot. The digestion solution was loaded and washed with ammonium carbonate solution $(10 \mathrm{mM}, \mathrm{pH} 10)$. The high $\mathrm{pH}$ is critical to remove DTT, which interferes with TMT labeling. Subsequently, the peptides were eluted with $60 \mathrm{vol} \%$ acetonitrile, collected, and dried in a vacuum centrifuge. After drying, the samples were redissolved in $100 \mu \mathrm{L}$ of phosphate buffer (100 mM, pH 7.4), and a $10 \mu \mathrm{L}$ aliquot was taken of each sample. These samples were used to prepare the pooled common reference samples: the main common reference consisted of an aliquot from every sample, three additional common references consisted of the pooled aliquots of the individual triplicates (CR1, CR2, and CR3). To $45 \mu \mathrm{L}$ of the remaining digests, $5 \mu \mathrm{L}$ of a solution of the synthetic peptide Ac-GDVEAGKK $(20 \mathrm{fmol} / \mu \mathrm{L}$, purchased from Pepscan, The Netherlands) was added as an internal standard to correct for any labeling or measurement bias. Every sample was labeled by addition of $4.5 \mu \mathrm{L}$ of a TMT label dissolved in acetonitrile $(7.3 \mu \mathrm{g} / \mu \mathrm{L})$ as depicted in Figure 1 and then incubated for $1 \mathrm{~h}$ at room temperature. Then $8 \mu \mathrm{L} 5$ vol \% hydroxylamine was added, and the resulting mixture was incubated for $1 \mathrm{~h}$ at room temperature. Subsequently, the samples were mixed as depicted in Figure 1. Samples of the various temperature treatments with the same digestion time were pooled along with the common references. CR1, CR2, and CR3 were labeled with labels TMT ${ }^{11}-130 \mathrm{~N}, \mathrm{TMT}^{11}-130 \mathrm{C}$, and $\mathrm{TMT}^{11}-131 \mathrm{~N}$. These three channels could be used for potential troubleshooting. The common reference of every sample (so, a mixture of every sample of all replicates) was labeled with label $\mathrm{TMT}^{11}-131 \mathrm{C}$. This common reference was used for relative quantification of every sample. After mixing, the samples were again subjected to SPE, but at low $\mathrm{pH}$ with $0.1 \mathrm{vol} \%$ formic acid for the initial washing and $60 \%$ acetonitrile with $0.1 \mathrm{vol} \%$ formic acid for the peptide collection. After drying, the peptides were dissolved in $550 \mu \mathrm{L} 0.1 \mathrm{vol} \%$ formic acid containing $1 \mathrm{fmol} / \mu \mathrm{L}$ angiotensin-I, angiotensin-III, and oxytocin as system suitability controls.

LC-MS. The $\mathrm{TMT}^{11}$-labeled peptides were analyzed by reversed-phase nanoscale LC-MS using a vented column system as described by Meiring et al. ${ }^{27}$ A $100 \mu \mathrm{m}$ i.d. $\times 20$ $\mathrm{mm} \mathrm{L}$ trapping column packed with $5 \mu \mathrm{m}$ Reprosil-Pur C18-AQ particles followed by a $50 \mu \mathrm{m}$ i.d. $\times 32.4 \mathrm{~cm} \mathrm{~L}$ analytical column packed with $3 \mu \mathrm{m}$ Reprosil-Pur C18-AQ particles were connected to an Agilent 1290 Infinity HPLC system. The samples were injected onto the trapping column and washed for $10 \mathrm{~min}$ with $0.1 \mathrm{vol} \%$ formic acid in water at a column flow rate of $5 \mu \mathrm{L} / \mathrm{min}$. Subsequently, the peptides were separated on the analytical column by a $30 \mathrm{~min}$ gradient from 6 to 56 vol \% acetonitrile containing $0.1 \mathrm{vol} \%$ formic acid at a column flow rate of $125 \mathrm{~nL} / \mathrm{min}$. The analytical column was coupled to a Fusion Lumos Tribrid mass spectrometer (Thermo Fisher) by electrospray ionization (spray tip prepared in-house). A targeted 
A

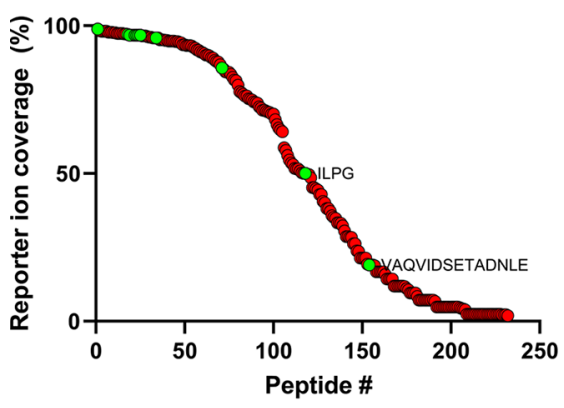

B

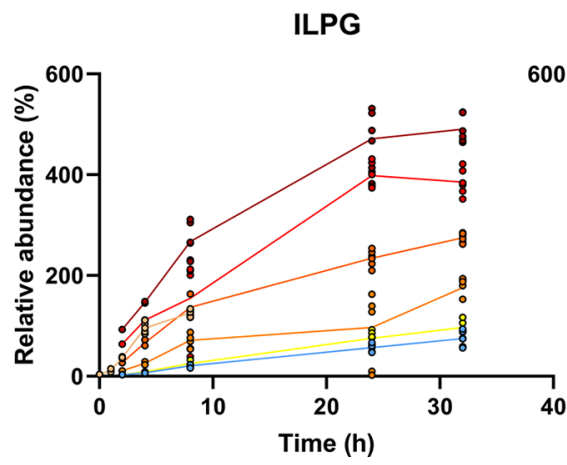

C VAQVIDSETADNLE

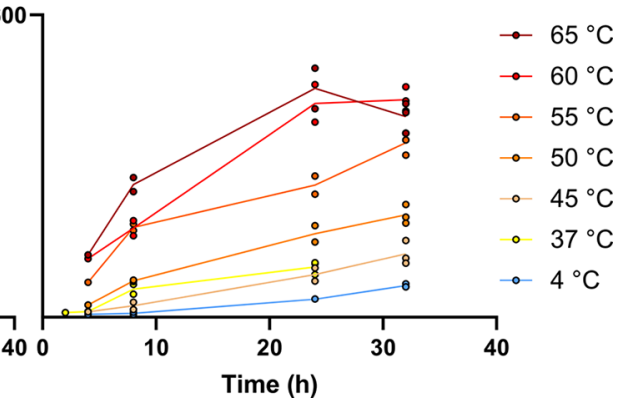

Figure 2. Peptide quantification quality. (A) The identified and quantified peptides sorted by TMT reporter ion coverage, expressed as the percentage of the total number of data points (462) where the reporter was detected. The selected peptides shown in Figure 3 are marked green. (B) Example of a kinetic plot of a peptide with 50\% reporter ion coverage (ILPG). (C) Example of a kinetic plot of a peptide with only 19\% reporter ion coverage (VAQVIDSETADNLE). For panels B and C, up to six data points per time point at a given temperature are expected (triplicates measured twice). The relative abundance compared to the average intensity of a particular peptide over all points (the common reference) is plotted over time for panels $\mathrm{B}$ and $\mathrm{C}$.

inclusion list was used to ensure quantification of the internal standard peptide, as well as some of the most abundant digestion products (DSIIR, GTNPVF, DGASRVV, DGASRVVL, HPELS, YPGLT, ESPNKTVS, VDENPLS). Detailed instrumental settings can be found in the Supporting Information.

Data Processing. The data was analyzed by Proteome Discoverer 2.4 SP1 (Thermo Fisher) to obtain the relative intensities of the internal standard peptide. Proteome Discoverer allows the user to set the TMT label modification to dynamic, which was required as the peptide Ac-GDVEAGKK was predominantly labeled on one lysine residue. The quan spectra were exported and filtered for the correct retention time and correction factors for every condition were determined. Subsequently, the data were processed by PEAKS $\mathrm{X}$ (Bioinformatics, Inc.) to quantify the DTd-derived peptides. The parent mass error tolerance was set to $5.0 \mathrm{ppm}$, the fragment mass error to $0.6 \mathrm{Da}$, and methionine oxidation and deamidation of asparagine and glutamine residues were considered as dynamic modifications. The quantitation module used $20 \mathrm{ppm}$ mass tolerance for the reporter ions and a peptide confidence cutoff of $-10 \log \mathrm{P}>15.0$. The peptide list was exported to Excel (Table S1) and after correction for the intensity of the AcGDVEAGKK reporter ions, the relative intensity of each reporter compared to the common reference was determined. To estimate the quantification quality (Figure 2), points that were either 0 or missing were counted as missing. For the plots in Figure 3, any point where no CR channel was available (most likely no MS3 spectrum acquired), no point is plotted and the line representing the average was automatically calculated with the remainder of the points. Final graphs were prepared by using GraphPad Prism 8.1.2.

\section{RESULTS AND DISCUSSION}

Diphtheria toxoid solutions were heated $(37,45,50,55,60,65$ ${ }^{\circ} \mathrm{C}$ ) for 2 days to obtain aberrant samples. The kinetics of the subsequent partial digestion of heated and $4{ }^{\circ} \mathrm{C}$ stored DTd solutions by cathepsin $\mathrm{S}$ was evaluated at seven time points. A total of 232 peptides were identified (confidence cutoff - $10 \log \mathrm{P}$ $>15.0$ ) and quantified, resulting in $70 \%$ coverage of the DTd sequence. However, most of these peptides were not measured at all of the 462 data points. To produce a meaningful kinetic plot for a specific peptide, its presence should be detectable at a sufficient number of data points. To visualize for which peptides a meaningful kinetic plot may be obtainable, the percentage of quantifiable TMT signals, i.e., the reporter ion coverage, was calculated for each of the 232 peptides (Figure 2A). For example, if at $t=0 \mathrm{~h}$ the intensity threshold for a single MS3 scan is not met because not enough peptide is present and no MS3 scan is obtained, this will decrease the reporter ion coverage by 2.3 percentage point (11/462 data points missing).

In total, 118 peptides had a reporter ion coverage of more than $50 \%$ of the data points. For these peptides, good kinetic profiles could be obtained, as shown in Figure 2B for peptide ILPG. Even peptides with a reporter ion coverage as low as $19 \%$ yielded useful kinetic information, as illustrated by peptide VAQVIDSETADNLE (Figure 2C). So, most of the peptides that were identified and quantified yielded useful information, emphasizing the robustness of the method. It may be beneficial to make an inclusion list to ensure that all peptides of interest are quantified in each sample. For instance, a screening run of the common reference sample could be analyzed first. However, this does remove some of the unbiased nature of the assay. To avoid missing unexpected peptides this screening would have to be done for every batch that is being analyzed. Furthermore, a low average intensity may result in excluding a peptide because peptides with a low MS1 intensity will require very long injection times to reach a sufficient ion count for MS3. However, low average intensity is commonly seen for intermediate cleavage products (e.g., LTEPLME in Figure 3), which are abundant only in a limited time frame but still provide useful insights in the enzymatic degradation process. Care should be taken to ensure that the use of an inclusion list fits the purpose of the experiment.

Prior to analyzing diphtheria toxoid samples, optimization experiments were performed to ensure maximum reproducibility, in particular with respect to differences in relative reporter ion intensity between MS3 scans. By direct infusion of $\mathrm{TMT}^{6}$ labeled synthetic peptide Ac-GDVEAGKK various settings were screened and low amounts of ions in the Orbitrap were found to be detrimental to the interscan reproducibility. Relatively high automatic gain control (AGC) settings combined with both sufficiently long injection times and MS1 intensity thresholds were required to reach these targets (Figure S1). To correct for any labeling efficiency, mixing variation or channel response differences, a fixed amount of internal standard peptide was 


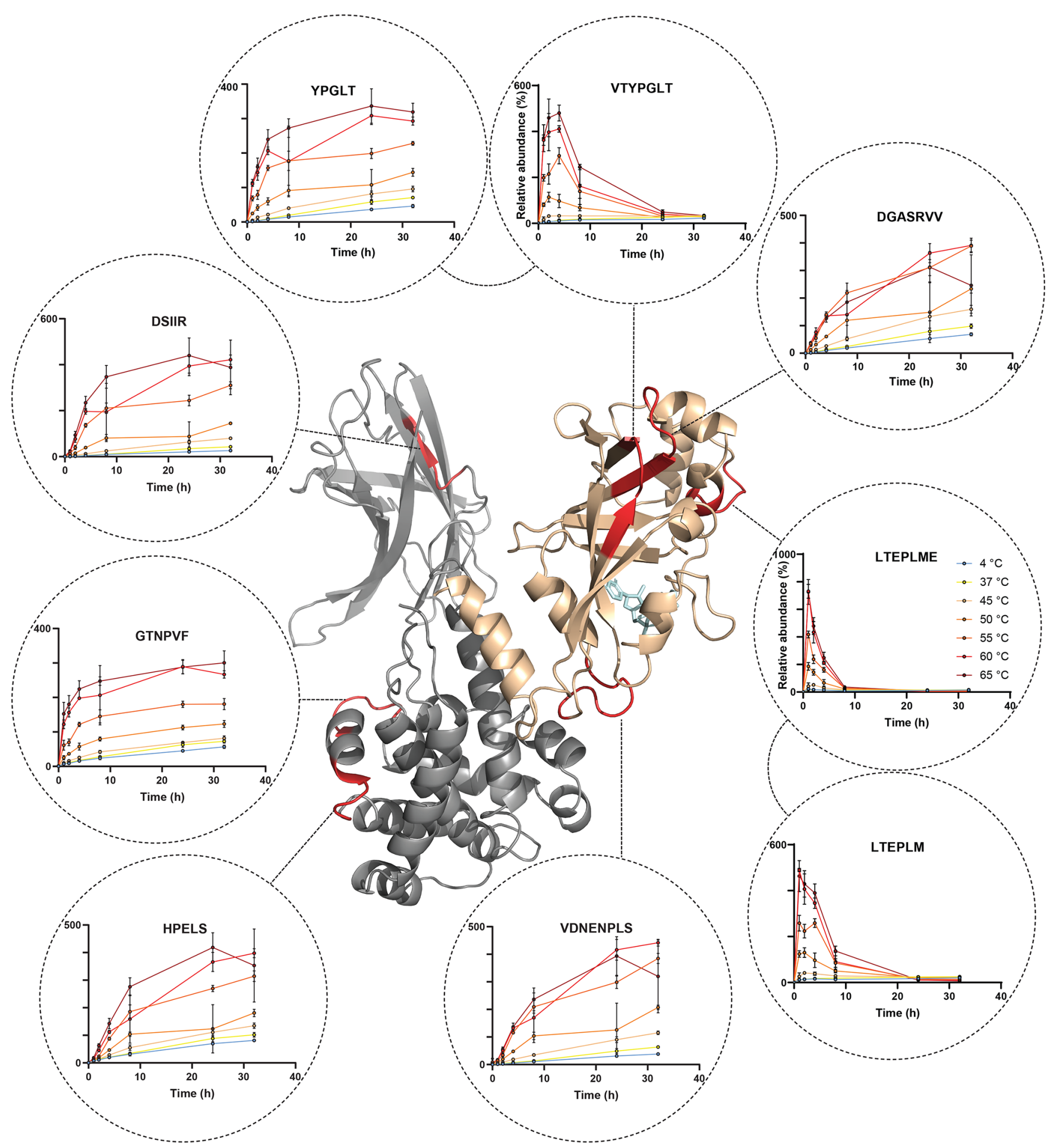

Figure 3. Kinetic profiles of a selection of representative peptides annotated to the diphtheria toxin crystal structure (PDB: 1DDT). The following color codes have been used: tan regions are part of the A fragment, gray regions are part of the B fragment and red is used to highlight the peptides. The relative abundance compared to the average intensity of a particular peptide over all points (the common reference) is plotted over time. Error bars represent the SD of the digestions of a diphtheria toxoid sample incubated and digested in triplicate that was measured in duplicate (i.e., six data points).

added to each sample. This resulted in good reproducibility between injections of the same sample (Figures S2 and S3).

A representative selection of peptides indicative of the formation of aberrant DTd upon temperature exposure is depicted in Figure 3. Peptides originating from different parts of the toxoid were all formed faster when exposed to higher temperatures. During the studied degradation timespan, this resulted in higher areas under the abundance-time curve. Three types of kinetics could be observed. In the first type, peptides such as VTYPGLT and LTEPLME are formed rapidly but are also degraded further into smaller peptides at the later time points. The peptide LTEPLM is of the same type, but the second phase, where degradation is faster than formation, is slower than for LTEPLME. Although we cannot determine with absolute 


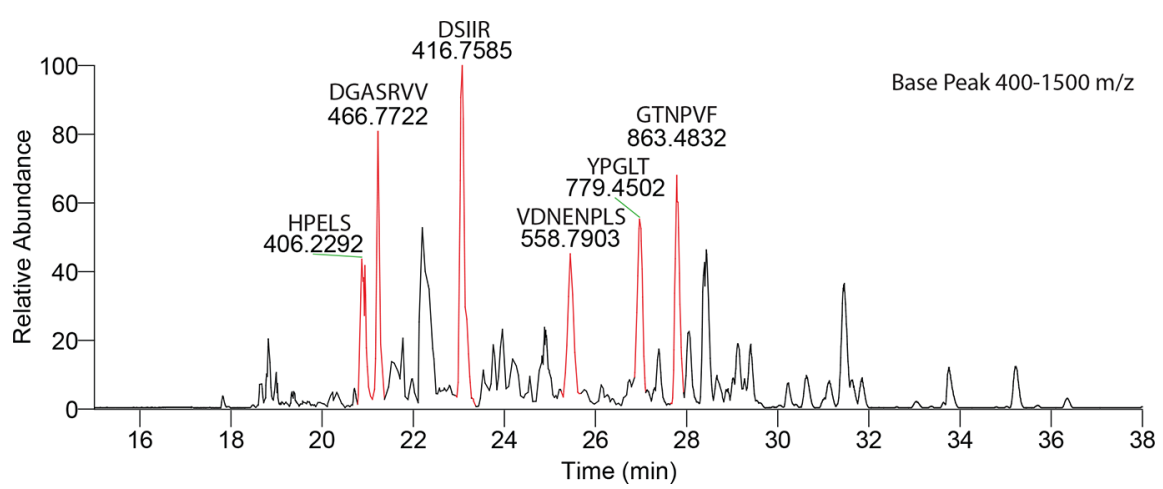

Figure 4. Base peak chromatogram of a pooled and TMT-labeled diphtheria toxoid after $32 \mathrm{~h}$ of cathepsin S digestion. The N-termini of the annotated peptides are TMT-labeled. The annotated peptides are those depicted in Figure 3 with increasing intensities over time.

certainty if a peptide is formed from the intact DTd or from an intermediate peptide, it is likely that the rapid formation and decrease of VTYPGLT is at least in part be responsible for the formation of YPGLT. YPGLT, DSIIR, and GTNPVF are part of the second type of kinetic profiles, where rapid formation in the first hours of digestion are followed by a slower second formation phase or steady state. These peptides are usually short and lack the hydrophobic branched amino acids in the middle or $\mathrm{N}$ terminal side of the peptide. Although cathepsin S should not be considered a completely selective endoprotease like trypsin, it has a strong preference for valine and leucine residues in the P2 position (and $\mathrm{P}^{\prime}$ and $\mathrm{P}^{\prime}$ or aromatic amino acids at $\mathrm{P} 3^{\prime}$ ) of the substrate. ${ }^{28}$ Peptides lacking this cleavage preference, or those that are too short, are often not cleaved further. This results in most peptides having a valine or leucine as the penultimate amino acid. Peptides with valine and leucine are more rare in the middle and further toward the $\mathrm{N}$ terminal side of the peptide, because such peptides are prone to cathepsin $S$ digestion at this location. The last type of kinetic profile involves a more steady increase of the peptide over time, such as observed with peptides DGASRVV, HPELS, or VDNENPLS. Because TMT quantification only gives relative intensities of the same peptide, a representative chromatogram of the TMT labeled and mixed sample after $32 \mathrm{~h}$ of digestion is depicted in Figure 4, to put the abundance of the peptides into perspective. A selection of the peptides shown in Figure 3 is highlighted in Figure 4, and these are among the most abundant peptides in the chromatogram.

Although it is not possible to directly correlate the formation kinetics of a single peptide or a group of peptides to in vivo efficacy or toxicity, these kinetics could be used for the development of an assay that measures consistency between batches without the use of animal studies. The current animal tests have notoriously high variability and insensitivity which makes direct comparison between new assays and animal tests difficult. ${ }^{29}$ Historic data has shown that toxoid vaccines are very stable when stored correctly, but exposure to elevated temperatures-similar to those used in the current studycan decrease the potency. ${ }^{30}$ Depending on how sensitive the chosen peptides are, the differences in kinetics can distinguish even changes in the toxoid induced by exposure to $37{ }^{\circ} \mathrm{C}$ compared to the controls. The formaldehyde-inactivation process also causes changes in structural stability ${ }^{31,32}$ and changes the susceptibility to enzymatic degradation by cathepsin S. ${ }^{9}$ It is therefore likely that a variety of batch-to-batch differences can also be detected in this type of assay.

From our current data, it is clear that peptides can be selected that could be used in a potential degradomics-based QC assay, similar to the assay described for tetanus toxoids. ${ }^{13}$ The selected peptides can be quantified, and deviation from the control value is indicative of denaturation of the toxoid. Important peptide selection criteria would be as follows: (i) on the basis of quantification of the peptide, it should be possible to distinguish heated samples from native samples; (ii) the concentration of the peptide candidate should increase over time; (iii) the peptide should be sufficiently abundant in the sample; and (iv) peptides containing unstable amino acid residues (e.g., asparagine) should be avoided, if possible. On the basis of these criteria, peptides YPGLT, DSIIR, and DGASRVV would be our suggested candidates for a degradomics-based QC assay for DTd. We recommend the use of our TMT-CR multiplexing strategy to identify peptides that fulfill the previously mentioned criteria. To subsequently develop a routine assay for batch-tobatch comparison and/or product stability testing, stable isotopically labeled internal (SIL) standard peptides can be used. Quantifying these three peptides after $20 \mathrm{~h}$ of exposure to cathepsin $S$ instead of measuring several time points is sufficient if the kinetic profiles have been mapped before. Acceptable quantification criteria should be set by the manufacturer for their specific products in subsequent studies and should, for instance, take into account their batch-to-batch variation. After confirming that peptides YPGLT DSIIR and DGASRVV can be used to pick up aberrant batches of a particular manufacturer's product, a full validation in accordance with the International Council for Harmonisation of Technical Requirements for Pharmaceuticals for Human Use (ICH) guidelines should be carried out. ${ }^{33}$ The use of SIL standards is more common in QC than using TMT labels because it is easy to monitor and it is transferable to more accessible Triple Stage Quadrupole mass spectrometers coupled to conventional liquid chromatography ${ }^{16}$ and will make the assay easier to validate.

Overall, the TMT-CR labeling strategy presented in this study allowed us to map the degradation kinetics of DTd when exposed to the cysteine protease cathepsin S. In order to distinguish mass spectrometer-errors from labeling or sample pretreatment errors, our 147 conditions were measured twice in a total of 42 runs for the sake of this study. However, measuring the triplicates only once would have been sufficient to map the degradation kinetics. In our case the common reference-based labeling strategy reduced the theoretical analysis time from almost a week to an overnight analysis. When employing all labels in the TMT 11-plex kit, a theoretical time reduction of $10 \times$ over label-free quantification is possible and a $15 \times$ reduction with TMTpro 16-plex, without being limited to one condition per channel. This dramatically reduces the analysis 
time and allows for a direct, relative comparison of different samples. The use of isobaric mass tagging in conjunction with the use of a common reference, as shown in this study, has a lot of potential and should be considered when reliable relative quantification of many parameters is required.

\section{ASSOCIATED CONTENT}

\section{SI Supporting Information}

The Supporting Information is available free of charge at https://pubs.acs.org/doi/10.1021/jasms.1c00070.

Orbitrap Fusion Lumos method summary (TXT)

Complete list of peptides with their relative intensities compared to the common reference (XLSX)

Supplementary Figures 1 and 2 illustrate the Reproducibility between injections of the same samples (Figures S1 and S2); MS3 scan's precision with various scan parameters (Figure S3) (PDF)

\section{AUTHOR INFORMATION}

\section{Corresponding Author}

Thomas J. M. Michiels - Division of BioTherapeutics, Leiden Academic Centre for Drug Research (LACDR), Leiden University, 2333 CC Leiden, The Netherlands; Intravacc, Institute for Translational Vaccinology, 3721 MA Bilthoven, The Netherlands; (1) orcid.org/0000-0003-1517-0312; Email: thomas.michiels@intravacc.nl

\section{Authors}

Madelief A. van Veen - Division of BioTherapeutics, Leiden Academic Centre for Drug Research (LACDR), Leiden University, 2333 CC Leiden, The Netherlands

Hugo D. Meiring - Intravacc, Institute for Translational Vaccinology, 3721 MA Bilthoven, The Netherlands

Wim Jiskoot - Division of BioTherapeutics, Leiden Academic Centre for Drug Research (LACDR), Leiden University, 2333 CC Leiden, The Netherlands

Gideon F. A. Kersten - Division of BioTherapeutics, Leiden Academic Centre for Drug Research (LACDR), Leiden University, 2333 CC Leiden, The Netherlands; Intravacc, Institute for Translational Vaccinology, 3721 MA Bilthoven, The Netherlands

Bernard Metz - Intravacc, Institute for Translational Vaccinology, 3721 MA Bilthoven, The Netherlands; (1) orcid.org/0000-0001-6814-7656

Complete contact information is available at: https://pubs.acs.org/10.1021/jasms.1c00070

\section{Notes}

The authors declare no competing financial interest.

\section{ACKNOWLEDGMENTS}

This work was performed within the Vac2Vac project supported by the Innovative Medicines Initiative 2 Joint Undertaking under Grant Agreement N-115924. We thank Wichard Tilstra for his assistance with the sample preparation and Marjolein Zohlandt for reviewing the manuscript.

\section{REFERENCES}

(1) Hartman, I. Z.; Kim, A.; Cotter, R. J.; Walter, K.; Dalai, S. K.; Boronina, T.; Griffith, W.; Lanar, D. E.; Schwenk, R.; Krzych, U.; Cole, R. N.; Sadegh-Nasseri, S. A reductionist cell-free major histocompat- ibility complex class II antigen processing system identifies immunodominant epitopes. Nat. Med. 2010, 16 (11), 1333-40.

(2) Egger, M.; Jurets, A.; Wallner, M.; Briza, P.; Ruzek, S.; Hainzl, S.; Pichler, U.; Kitzmuller, C.; Bohle, B.; Huber, C. G.; Ferreira, F. Assessing protein immunogenicity with a dendritic cell line-derived endolysosomal degradome. PLoS One 2011, 6 (2), No. e17278.

(3) Schulten, V.; Nagl, B.; Scala, E.; Bernardi, M. L.; Mari, A.; Ciardiello, M. A.; Lauer, I.; Scheurer, S.; Briza, P.; Jurets, A.; Ferreira, F.; Jahn-Schmid, B.; Fischer, G. F.; Bohle, B. Pru p 3, the nonspecific lipid transfer protein from peach, dominates the immune response to its homolog in hazelnut. Allergy 2011, 66 (8), 1005-13.

(4) Ackaert, C.; Kofler, S.; Horejs-Hoeck, J.; Zulehner, N.; Asam, C.; von Grafenstein, S.; Fuchs, J. E.; Briza, P.; Liedl, K. R.; Bohle, B.; Ferreira, F.; Brandstetter, H.; Oostingh, G. J.; Duschl, A. The impact of nitration on the structure and immunogenicity of the major birch pollen allergen Bet v 1.0101. PLoS One 2014, 9 (8), No. e104520.

(5) Machado, Y.; Freier, R.; Scheiblhofer, S.; Thalhamer, T.; Mayr, M.; Briza, P.; Grutsch, S.; Ahammer, L.; Fuchs, J. E.; Wallnoefer, H. G.; Isakovic, A.; Kohlbauer, V.; Hinterholzer, A.; Steiner, M.; Danzer, M.; Horejs-Hoeck, J.; Ferreira, F.; Liedl, K. R.; Tollinger, M.; Lackner, P.; Johnson, C. M.; Brandstetter, H.; Thalhamer, J.; Weiss, R. Fold stability during endolysosomal acidification is a key factor for allergenicity and immunogenicity of the major birch pollen allergen. J. Allergy Clin. Immunol. 2016, 137 (5), 1525-34.

(6) Freier, R.; Dall, E.; Brandstetter, H. Protease recognition sites in Bet $\mathrm{v}$ 1a are cryptic, explaining its slow processing relevant to its allergenicity. Sci. Rep. 2015, 5, 12707.

(7) Kitzmuller, C.; Zulehner, N.; Roulias, A.; Briza, P.; Ferreira, F.; Fae, I.; Fischer, G. F.; Bohle, B. Correlation of sensitizing capacity and $\mathrm{T}$-cell recognition within the Bet v 1 family. J. Allergy Clin. Immunol. 2015, 136 (1), 151-8.

(8) Kitzmuller, C.; Wallner, M.; Deifl, S.; Mutschlechner, S.; Walterskirchen, C.; Zlabinger, G. J.; Ferreira, F.; Bohle, B. A hypoallergenic variant of the major birch pollen allergen shows distinct characteristics in antigen processing and T-cell activation. Allergy 2012, 67 (11), 1375-82.

(9) Michiels, T. J. M.; Meiring, H. D.; Jiskoot, W.; Kersten, G. F. A.; Metz, B. Formaldehyde treatment of proteins enhances proteolytic degradation by the endo-lysosomal protease cathepsin S. Sci. Rep. 2020, 10 (1), 11535.

(10) Ghimire, T. R.; Benson, R. A.; Garside, P.; Brewer, J. M. Alum increases antigen uptake, reduces antigen degradation and sustains antigen presentation by DCs in vitro. Immunol. Lett. 2012, 147 (1-2), $55-62$.

(11) Delamarre, L.; Couture, R.; Mellman, I.; Trombetta, E. S. Enhancing immunogenicity by limiting susceptibility to lysosomal proteolysis. J. Exp. Med. 2006, 203 (9), 2049-55.

(12) Delamarre, L.; Pack, M.; Chang, H.; Mellman, I.; Trombetta, E. S. Differential lysosomal proteolysis in antigen-presenting cells determines antigen fate. Science 2005, 307 (5715), 1630-4.

(13) Michiels, T.J. M.; Tilstra, W.; Hamzink, M. R. J.; de Ridder, J. W.; Danial, M.; Meiring, H. D.; Kersten, G. F. A.; Jiskoot, W.; Metz, B. Degradomics-Based Analysis of Tetanus Toxoids as a Quality Control Assay. Vaccines 2020, 8 (4), 712.

(14) Metz, B.; Michiels, T.; Uittenbogaard, J.; Danial, M.; Tilstra, W.; Meiring, H. D.; Hennink, W. E.; Crommelin, D. J. A.; Kersten, G. F. A.; Jiskoot, W. Identification of formaldehyde-induced modifications in diphtheria toxin. J. Pharm. Sci. 2020, 109, 543.

(15) DeLange, R. J.; Williams, L. C.; Drazin, R. E.; Collier, R. J. The amino acid sequence of fragment $A$, an enzymically active fragment of diphtheria toxin. III. The chymotryptic peptides, the peptides derived by cleavage at tryptophan residues, and the complete sequence of the protein. J. Biol. Chem. 1979, 254 (13), 5838-42.

(16) Bozovic, A.; Kulasingam, V. Quantitative mass spectrometrybased assay development and validation: from small molecules to proteins. Clin. Biochem. 2013, 46 (6), 444-55.

(17) Rauniyar, N.; Yates, J. R., 3rd Isobaric labeling-based relative quantification in shotgun proteomics. J. Proteome Res. 2014, 13 (12), 5293-309. 
(18) Arul, A. B.; Robinson, R. A. S. Sample Multiplexing Strategies in Quantitative Proteomics. Anal. Chem. 2019, 91 (1), 178-189.

(19) Thompson, A.; Schafer, J.; Kuhn, K.; Kienle, S.; Schwarz, J.; Schmidt, G.; Neumann, T.; Johnstone, R.; Mohammed, A. K.; Hamon, C. Tandem mass tags: a novel quantification strategy for comparative analysis of complex protein mixtures by MS/MS. Anal. Chem. 2003, 75 (8), 1895-904.

(20) Thompson, A.; Wolmer, N.; Koncarevic, S.; Selzer, S.; Bohm, G.; Legner, H.; Schmid, P.; Kienle, S.; Penning, P.; Hohle, C.; Berfelde, A.; Martinez-Pinna, R.; Farztdinov, V.; Jung, S.; Kuhn, K.; Pike, I. TMTpro: Design, Synthesis, and Initial Evaluation of a Proline-Based Isobaric 16-Plex Tandem Mass Tag Reagent Set. Anal. Chem. 2019, 91 (24), 15941-15950.

(21) Kim, H.; Zhao, B.; Snesrud, E. C.; Haas, B. J.; Town, C. D.; Quackenbush, J. Use of RNA and genomic DNA references for inferred comparisons in DNA microarray analyses. BioTechniques 2002, 33 (4), 924-30.

(22) van de Waterbeemd, B.; Mommen, G. P.; Pennings, J. L.; Eppink, M. H.; Wijffels, R. H.; van der Pol, L. A.; de Jong, A. P. Quantitative proteomics reveals distinct differences in the protein content of outer membrane vesicle vaccines. J. Proteome Res. 2013, 12 (4), 1898-908.

(23) Plubell, D. L.; Wilmarth, P. A.; Zhao, Y.; Fenton, A. M.; Minnier, J.; Reddy, A. P.; Klimek, J.; Yang, X.; David, L. L.; Pamir, N. Extended Multiplexing of Tandem Mass Tags (TMT) Labeling Reveals Age and High Fat Diet Specific Proteome Changes in Mouse Epididymal Adipose Tissue. Mol. Cell Proteomics 2017, 16 (5), 873-890.

(24) Dou, Y.; Kawaler, E. A.; Cui Zhou, D.; Gritsenko, M. A.; Huang, C.; Blumenberg, L.; Karpova, A.; Petyuk, V. A.; Savage, S. R.; Satpathy, S.; Liu, W.; Wu, Y.; Tsai, C. F.; Wen, B.; Li, Z.; Cao, S.; Moon, J.; Shi, Z.; Cornwell, M.; Wyczalkowski, M. A.; Chu, R. K.; Vasaikar, S.; Zhou, H.; Gao, Q.; Moore, R. J.; Li, K.; Sethuraman, S.; Monroe, M. E.; Zhao, R.; Heiman, D.; Krug, K.; Clauser, K.; Kothadia, R.; Maruvka, Y.; Pico, A. R.; Oliphant, A. E.; Hoskins, E. L.; Pugh, S. L.; Beecroft, S. J. I.; Adams, D. W.; Jarman, J. C.; Kong, A.; Chang, H. Y.; Reva, B.; Liao, Y.; Rykunov, D.; Colaprico, A.; Chen, X. S.; Czekanski, A.; Jedryka, M.; Matkowski, R.; Wiznerowicz, M.; Hiltke, T.; Boja, E.; Kinsinger, C. R.; Mesri, M.; Robles, A. I.; Rodriguez, H.; Mutch, D.; Fuh, K.; Ellis, M. J.; DeLair, D.; Thiagarajan, M.; Mani, D. R.; Getz, G.; Noble, M.; Nesvizhskii, A. I.; Wang, P.; Anderson, M. L.; Levine, D. A.; Smith, R. D.; Payne, S. H.; Ruggles, K. V.; Rodland, K. D.; Ding, L.; Zhang, B.; Liu, T.; Fenyo, D.; Clinical Proteomic Tumor Analysis, C. Proteogenomic Characterization of Endometrial Carcinoma. Cell 2020, 180 (4), 729-748.

(25) Satpathy, S.; Jaehnig, E. J.; Krug, K.; Kim, B. J.; Saltzman, A. B.; Chan, D. W.; Holloway, K. R.; Anurag, M.; Huang, C.; Singh, P.; Gao, A.; Namai, N.; Dou, Y.; Wen, B.; Vasaikar, S. V.; Mutch, D.; Watson, M. A.; Ma, C.; Ademuyiwa, F. O.; Rimawi, M. F.; Schiff, R.; Hoog, J.; Jacobs, S.; Malovannaya, A.; Hyslop, T.; Clauser, K. R.; Mani, D. R.; Perou, C. M.; Miles, G.; Zhang, B.; Gillette, M. A.; Carr, S. A.; Ellis, M. J. Microscaled proteogenomic methods for precision oncology. Nat. Commun. 2020, 11 (1), 532.

(26) VAC2VAC Consortium website. http://www.vac2vac.eu/ (accessed 2020-10-16).

(27) Meiring, H. D.; van der Heeft, E.; Ten Hove, G. J.; de Jong, A. P. J. M. Nanoscale LC-MS(n): technical design and applications to peptide and protein analysis. J. Sep. Sci. 2002, 25 (9), 557-568.

(28) Neil, D.; Rawlings, G. S. S. Handbook of Proteolytic Enzymes; Academic Press, 2013; Vol. 2, p 4094.

(29) Stalpers, C. A. L.; Retmana, I. A.; Pennings, J. L. A.; Vandebriel, R. J.; Hendriksen, C. F. M.; Akkermans, A. M.; Hoefnagel, M. H. N., Variability of in vivo potency tests of Diphtheria, Tetanus and acellular Pertussis (DTaP) vaccines. Vaccine 2021.392506

(30) Milstein, J. B. Temperature Sensitivity of Vaccines;; World Health Organization: 2006; WHO/IVB/06.10.

(31) Metz, B.; Jiskoot, W.; Hennink, W. E.; Crommelin, D. J.; Kersten, G. F. Physicochemical and immunochemical techniques predict the quality of diphtheria toxoid vaccines. Vaccine 2003, 22 (2), 156-67.

(32) Paliwal, R.; London, E. Comparison of the conformation, hydrophobicity, and model membrane interactions of diphtheria toxin to those of formaldehyde-treated toxin (diphtheria toxoid): formaldehyde stabilization of the native conformation inhibits changes that allow membrane insertion. Biochemistry 1996, 35 (7), 2374-9.

(33) ICH Q2(R1) Validation of Analytical Procedures: Text and Methodology. https://ich.org/page/quality-guidelines (accessed 2021-04-19). 